\title{
Interleukin 22 and 6 serum concentrations decrease under long-term biologic therapy in psoriasis
}

\author{
Irmina Olejniczak-Staruch ${ }^{1}$, Joanna Narbutt², Igor Bednarski², Anna Woźniacka ${ }^{1}$, Joanna Sieniawska1, \\ Marzena Kraska-Gacka' ${ }^{1}$, Janusz Śmigielski ${ }^{3}$, Aleksandra Lesiak ${ }^{2}$
}

${ }^{1}$ Department of Dermatology and Venereology, Medical University of Lodz, Lodz, Poland 2Department of Dermatology, Pediatric Dermatology and Dermatological Oncology, Medical University of Lodz, Lodz, Poland ${ }^{3}$ State Higher Vocational School, Konin, Poland

\author{
Adv Dermatol Allergol 2020; XXXVII (5): 705-711
} DOI: https://doi.org/10.5114/ada.2020.100481

\begin{abstract}
Introduction: Psoriasis, affecting approximately $2 \%$ of the worldwide population, is a chronic, inflammatory skin disease in which overexpression of proinflammatory cytokines is observed. Most of the available data on the influence of antipsoriatic therapy on the cytokine serum concentration are inconsistent and based on short-term observations.

Aim: To evaluate the influence of long-term biologic therapy with tumor necrosis factor $\alpha$ (TNF- $\alpha$ ) blockers (adalimumab, etanercept, infliximab) and IL-12/23 inhibitor (ustekinumab) on the level of IL-6, IL-22 in the sera of patients with psoriasis.

Material and methods: Blood samples were collected from 42 psoriatic patients in order to determine IL-6 and IL-22 serum concentrations prior to and at the $3^{\text {rd }}, 12^{\text {th }}, 24^{\text {th }}$ and $36^{\text {th }}$ month of biologic therapy. Psoriasis Activity and Severity Index (PASI) was assessed at the same time points. The control group consisted of 30 sex- and age-matched healthy volunteers.

Results: Mean PASI index at baseline was $14.49 \pm 3.69$ and decreased significantly until the end of the observation. Mean IL-6 serum concentration decreased significantly in all study groups $(p<0.05)$. A statistically significant decrease in IL-22 concentrations was demonstrated during the treatment with adalimumab and infliximab but not etanercept or ustekinumab.

Conclusions: According to obtained results, IL-6 and IL-22 serum concentration may be an accurate marker of response to antipsoriatic therapy, even though not correlated with PASI index. Biologic therapy in psoriasis allows for long-term clinical improvement expressed not only by the remission of skin lesions, but also by lowering serum concentrations of pro-inflammatory interleukins.
\end{abstract}

Key words: interleukin 22, interleukin 6, psoriasis, biologic therapy.

\section{Introduction}

Psoriasis, affecting approximately $2 \%$ of the worldwide population, is a chronic, inflammatory skin disease characterized by the presence of hyperkeratotic papules confluent in the plaques located in typical body areas [1]. Pathogenesis of this dermatosis is still not fully elucidated. Initially, it was thought to be a disease mediated by Th1 lymphocytes [2, 3]. However, numerous studies on its pathogenesis in recent years have provided evidence for the key contribution of Th17 lymphocytes and proinflammatory cytokines secreted by them $[4,5]$. Better understanding of psoriasis pathogenesis has resulted in the search for new effective therapies directed against selected components of the inflammatory cascade leading to the development of typical skin lesions. Genetically engineered monoclonal antibodies act selectively to achieve high clinical efficacy with a relatively low risk of side effects. Subsequent clinical trials have led to the widespread use of biological drugs that have revolutionized the treatment approach in psoriasis. These molecules directed against key cytokines in the development of psoriasis include e.g. tumor necrosis factor $\alpha$ (TNF- $\alpha$ ) blockers (infliximab, etanercept, adalimumab) and p40 (subunit IL-12/23) inhibitor (ustekinumab). Recently more reports have been available on the safety and efficacy

Address for correspondnece: Irmina Olejniczak-Staruch MD, Department of Dermatology and Venereology, Medical University of Lodz, e-mail: olejniczak.staruch@gmail.com

Received: 15.01.2019, accepted: 2.03.2019. 
of the formulations in long-term use. However only few reports provide data from the daily clinical practice observations.

Markers of effectiveness and prognosis in the treatment of psoriasis are still being sought. Expression of a number of proinflammatory cytokines, as proven, is elevated in both the skin and serum of psoriatic patients $[6,7]$. Numerous studies also indicate a change in their concentrations under the influence of effective therapy of this dermatosis [8-11]. However, their results are often inconsistent and based on short-term observations.

\section{Aim}

The aim of the study was to evaluate the influence of long-term biologic therapy with TNF- $\alpha$ blockers (adalimumab, etanercept, infliximab) and interleukin IL-12/23 inhibitor (ustekinumab) on the level of IL-6, IL-22 in sera of patients with psoriasis.

\section{Material and methods}

The study group consisted of 42 (25 male and $17 \mathrm{fe}$ male, mean age: $52 \pm 11$ years) patients with moderateto-severe plaque psoriasis treated with biologic therapy in the Department of Dermatology and Venereology of Medical University of Lodz for 36 months. The control group consisted of 30 healthy people matched in terms of sex and age. Characteristics of the study group are presented in Table 1.

Blood samples were collected from the patients in order to determine IL- 6 and IL-22 levels prior to and at the $3^{\text {rd }}, 12^{\text {th }}, 24^{\text {th }}$ and $36^{\text {th }}$ month of biologic therapy. Subsequently they were stored at room temperature for a clot to form. After centrifugation at about $500 \mathrm{rpm}$ for $15 \mathrm{~min}$ to separate serum, aliquots of the samples were stored frozen at $-20^{\circ} \mathrm{C}$ until the measurement of cytokines concentration was performed.
The level of IL-6 and IL-22 serum was measured by enzyme-linked immunospecific assay ELISA (Quantikine ${ }^{\oplus}$, R \& D Systems, Inc., Minneapolis, USA).

Efficacy of the therapy was assessed by the use of Psoriasis Activity and Severity Index (PASI) at the beginning and in the $3^{\text {rd }}, 12^{\text {th }}, 24^{\text {th }}$ and $36^{\text {th }}$ month of the therapy.

The experimental plan was conducted according to the Declaration of Helsinki principles. Research has been approved by the bioethics committee of the Medical University of Lodz, Poland. All of the participants signed informed consent to take part in the study before any study procedure.

\section{Statistical analysis}

All analyses were performed using Statistica 13 software (StatSoft Inc., Tulsa, OK, USA). Intergroup differences for each variable were analyzed using both the Friedman test (nonparametric ANOVA) and repeated measures ANOVA followed by Mauchly's sphericity test and, if necessary, Greenhouse-Geisser/Huynh-Feldt correction and multivariate tests (Wilks lambda). Differences between groups were compared using an unpaired Welch's t-test if the data showed a normal distribution; otherwise the Mann-Whitney $U$ test was used. Data are expressed as mean \pm SEM, and a $p$-value of 0.05 or less was considered as statistically significant. Multivariate regression was applied to check the possible relationship between PASI and interleukin concentration at all time points.

\section{Results}

The PASI in the entire study group before treatment was $14.49 \pm 3.69$. After a 3-month follow-up period, patients receiving biologic therapy showed a significant reduction in the severity of skin lesions expressed in the PASI index in all treatment groups (Table 2). The clini-

Table 1. Characteristics of the study group and the control group

\begin{tabular}{|c|c|c|c|c|c|}
\hline Parameter & Adalimumab & Etanercept & Infliximab & Ustekinumab & Control group \\
\hline$N$ & $19(7 \mathrm{~F}, 12 \mathrm{M})$ & $11(5 \mathrm{~F}, 7 \mathrm{M})$ & $7(5 \mathrm{~F}, 2 \mathrm{M})$ & $5(3 F, 2 M)$ & $30(11 \mathrm{~F}, 19 \mathrm{M})$ \\
\hline Age [years] (mean \pm SEM) & $48.6 \pm 13.4$ & $50.6 \pm 11.5$ & $49.9 \pm 12.5$ & $47 \pm 15.3$ & $45.4 \pm 10.1$ \\
\hline Psoriasis duration [years] (mean \pm SEM) & $18.8 \pm 10.2$ & $18.0 \pm 13.2$ & $23.3 \pm 13.4$ & $22.4 \pm 14.8$ & - \\
\hline Hypertension (\%) & $10(52.6)$ & $5(45.5)$ & $4(57.1)$ & $2(40)$ & $8(26.6)$ \\
\hline Cardiovascular disease (\%) & $3(15.8)$ & $1(9.1)$ & $1(14.3)$ & $1(20)$ & $2(6.7)$ \\
\hline History of myocardial infarction (\%) & $1(5.2)$ & 0 & 0 & $1(20)$ & 0 \\
\hline Diabetes mellitus (\%) & $1(5.2)$ & $1(9.1)$ & 0 & $2(40)$ & $1(3.3)$ \\
\hline Glaucoma (\%) & $1(5.2)$ & $1(9.1)$ & 0 & 0 & 0 \\
\hline Cigarette smoking (\%) & $7(36.8)$ & $5(45.5)$ & $2(28.6)$ & $2(40)$ & $3(10)$ \\
\hline
\end{tabular}


Table 2. Changes in PASI index during study treatment

\begin{tabular}{lcccccc}
\hline Study group & Baseline & $3^{\text {rd }}$ month & 12 $^{\text {th }}$ month & 24 $^{\text {th }}$ month & 36 $^{\text {th }}$ month & Repeated measures \\
\hline Adalimumab & $15.12 \pm 0.94$ & $3.13 \pm 0.63$ & $2.38 \pm 0.48$ & $2.72 \pm 0.27$ & $2.98 \pm 0.41$ & $<0.0001^{*}$ \\
\hline Etanercept & $13.90 \pm 3.41$ & $3.81 \pm 3.44$ & $3.28 \pm 2.03$ & $1.96 \pm 1.38$ & $2.52 \pm 0.60$ & $0.0001^{*}$ \\
\hline Infliximab & $13.514 \pm 4.03$ & $5.10 \pm 5.37$ & $3.90 \pm 3.16$ & $2.51 \pm 2.95$ & $2.84 \pm 2.30$ & $0.0022^{*}$ \\
\hline Ustekinumab & $14.76 \pm 2.50$ & $2.72 \pm 3.56$ & $1.82 \pm 0.98$ & $2.62 \pm 2.07$ & $2.30 \pm 1.44$ & $0.0261^{*}$ \\
\hline
\end{tabular}

Data shown as means \pm SEM. *Statistically significant findings.

Table 3. IL-22 (pg/ml) serum levels in the control group and in the psoriasis group at baseline and at the $3^{\text {rd }}, 12^{\text {th }}, 24^{\text {th }}$, $36^{\text {th }}$ month of biologic therapy

\begin{tabular}{lccccccc}
\hline Study group & Baseline & $3^{\text {rd }}$ month & 12 $^{\text {th }}$ month & 24 $^{\text {th }}$ month & $3^{\text {th }}$ month & $\begin{array}{c}\text { Control vs. } \\
\text { baseline }\end{array}$ & $\begin{array}{c}\text { Repeated } \\
\text { measures }\end{array}$ \\
\hline Control & $11.40 \pm 1.27$ & & & & & & \\
\hline Adalimumab & $47.69 \pm 12.68$ & $36.90 \pm 7.35$ & $30.54 \pm 4.12$ & $27.81 \pm 3.71$ & $28.5 \pm 4.12$ & $0.0102^{*}$ & $0.0001^{*}$ \\
\hline Etanercept & $23.01 \pm 16.05$ & $23.65 \pm 18.15$ & $20.63 \pm 15.49$ & $19.78 \pm 12.64$ & $17.22 \pm 13.00$ & $0.0375^{*}$ & 0.3642 \\
\hline Infliximab & $69.34 \pm 61.34$ & $37.15 \pm 25.15$ & $24.01 \pm 16.90$ & $20.62 \pm 11.19$ & $20.73 \pm 10.35$ & 0.0595 & $0.0055^{*}$ \\
\hline Ustekinumab & $20.18 \pm 16.07$ & $21.96 \pm 14.67$ & $24.08 \pm 22.42$ & $12.00 \pm 11.27$ & $11.78 \pm 12.86$ & 0.2846 & 0.3362
\end{tabular}

Data shown as means \pm SEM. *Statistically significant findings.

cal effect lasted until the $36^{\text {th }}$ month of therapy with all studied agents.

The non-parametric Friedman test showed differences between the recurring IL-22 mean values and the value of $\chi^{2}$ of 22.89 , which was statistically significant ( $p=0.0001)$ in patients receiving adalimumab. A statistically significant decrease in IL-22 concentrations was also demonstrated during the treatment with infliximab but not etanercept ( $p=0.3642)$ or ustekinumab $(p=0.3362)$ (Table 3, Figure 1).

Statistical analysis of mean IL-6 serum concentrations revealed a significant decrease in all study groups $(p<0.05)$ (Table 4, Figure 2). Results of post-hoc (Tukey or Dunn's) test for each study group are presented in Table 5.

To check whether IL-6/IL-22 serum concentration influences PASI score we used the multivariate regression model. In all estimations, p-value was above the level of statistical significance (Table 6).

\section{Discussion}

Psoriasis pathogenesis is still not fully elucidated. Recent studies provide evidence for the involvement of the immune system in the development of psoriasis $[12,13]$. Better understanding of psoriasis enabled the invention of the therapies selectively inhibiting action of the molecules involved in the development of psoriasis [14-16]. The effectiveness of biologic therapy has been demonstrated so far not only on the basis of clinical improvement in skin lesions, but also on the molecular level - resulting in a decrease in markers of inflammation in both the skin and sera of the treated patients.
IL-22, produced by skin c-Kit+Fc RI+ mast cells, Th17, Th22 and Tc22 cells (CD8+ T cells) is the main cytokine involved in excessive keratinocyte proliferation observed in psoriasis $[17,18]$.

Infiltration of effector cells $\mathrm{T}$ in psoriatic plaques result in massive production of $\mathrm{IL}-22$ which binds to its receptor highly expressed on keratinocytes $[19,20]$. It results in Janus kinase activation, which is a signal transducer and activator of transcription STAT3 and mitogenic activating peptide kinase pathways [21].

Numerous studies showed an increase in IL-22 concentration both within the skin lesions and sera of patients with psoriasis when compared to healthy subjects $[6,7]$. We also observed that mean IL-22 serum concentration at baseline in the group treated with adalimumab and etanercept was significantly higher than in the control group $(p<0.05)$. These changes were not statistically significant between infliximab and ustekinumab group in comparison to healthy subjects, which is probably caused by a relatively smaller number of participants in these groups $(p>0.05)$. In the majority of previous studies, a positive correlation between the PASI index and the serum IL-22 concentration was found [7, 22], however, in some of them, as in our observations, no relationship between the severity of the disease and the serum level of this cytokine was observed [6,8].

Numerous studies investigating the effect of psoriatic treatment on IL-22 in patients gave inconclusive results. The influence of short-term anti-TNF- $\alpha$ therapy on the IL-22 serum concentration was investigated by Luan et al. [7]. IL-22 was significantly higher than in healthy controls 

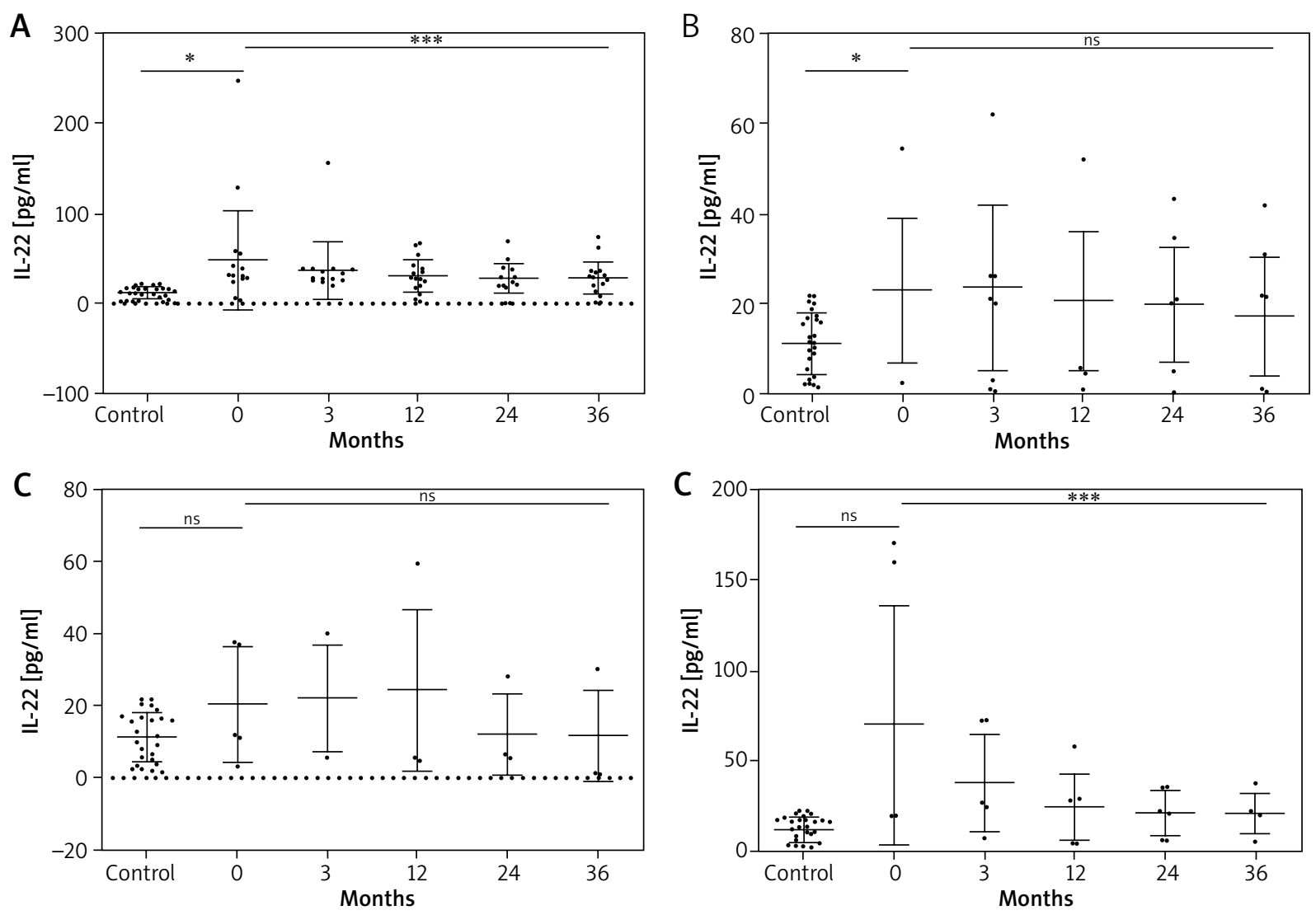

Figure 1. Changes in the IL-22 serum level during biological treatment (A - adalimumab, $\mathbf{B}$ - etanercept, $\mathbf{C}-$ ustekinumab, D - infliximab). Data shown as means $\pm \mathrm{SEM},{ }^{*} p<0.05,{ }^{* *} p<0.01,{ }^{* * *} p<0.001$

Table 4. IL-6 $(\mathrm{pg} / \mathrm{ml})$ serum levels in the control group and in the psoriasis group at baseline and at the $3^{\text {rd }}, 12^{\text {th }}, 24^{\text {th }}$, $36^{\text {th }}$ month of biologic therapy

\begin{tabular}{lccccccc}
\hline Study group & Baseline & $3^{\text {rd }}$ month & $\mathbf{1 2}^{\text {th }}$ month & $\mathbf{2 4}^{\text {th }}$ month & $\mathbf{3 6}^{\text {th }}$ month & $\begin{array}{c}\text { Control vs. } \\
\text { baseline }\end{array}$ & $\begin{array}{c}\text { Repeated } \\
\text { measures }\end{array}$ \\
\hline Control & $6.53 \pm 2.13$ & & & & & & \\
\hline Adalimumab & $5.58 \pm 1.34$ & $3.21 \pm 0.49$ & $2.65 \pm 0.53$ & $2.65 \pm 0.45$ & $2.88 \pm 0.52$ & 0.6473 & $0.0003^{*}$ \\
\hline Etanercept & $10.12 \pm 9.76$ & $2.47 \pm 2.24$ & $4.00 \pm 3.99$ & $3.00 \pm 2.34$ & $3.22 \pm 2.73$ & 0.3455 & $0.0093^{*}$ \\
\hline Infliximab & $20.34 \pm 30.59$ & $11.20 \pm 15.69$ & $21.26 \pm 38.68$ & $16.10 \pm 29.79$ & $7.32 \pm 9.77$ & 0.3195 & $0.0157^{*}$ \\
\hline Ustekinumab & $6.26 \pm 2.87$ & $12.27 \pm 15.36$ & $4.41 \pm 2.24$ & $5.31 \pm 4.42$ & $4.74 \pm 2.79$ & 0.8587 & $0.0043^{*}$ \\
\hline
\end{tabular}

Data shown as means \pm SEM. *Statistically significant findings.

and a 12-week therapy with adalimumab resulted in its significant decrease.

A significant $(p<0.05)$ reduction in IL-22 serum concentration after a 12-week therapy with etanercept, but not with the acitretin was observed by Caproni et al. [8]. In the study conducted by Cordiali-Fei et al. [9], a 24week therapy with anti-TNF- $\alpha$ agents (etanercept, adalimumab and infliximab) in 59 psoriatic patients resulted in a significant reduction in IL-22 serum concentration in all study groups, which is consistent with our results.

This can be explained by the fact that TNF- $\alpha$ blockade results in inhibition of IL-22 secretion by effector T lym- phocytes and thus causes reduction in its concentration both in skin lesions and in patients sera. Lowering the concentration of IL-22 under the influence of biological drugs results from the mechanism of their action and is not only a simple reflection of their clinical effectiveness expressed by PASI reduction. Therefore, as shown in the study conducted by Caproni et al. [8], acitretin, due to the different mechanism of action (reduction of epidermal hyperkeratosis), does not affect the serum concentration of IL-22.

Balato et al. [23] demonstrated an increased mRNA expression for IL-22 in lesional skin of psoriatic patients when compared to non-lesional skin and skin biopsies of 

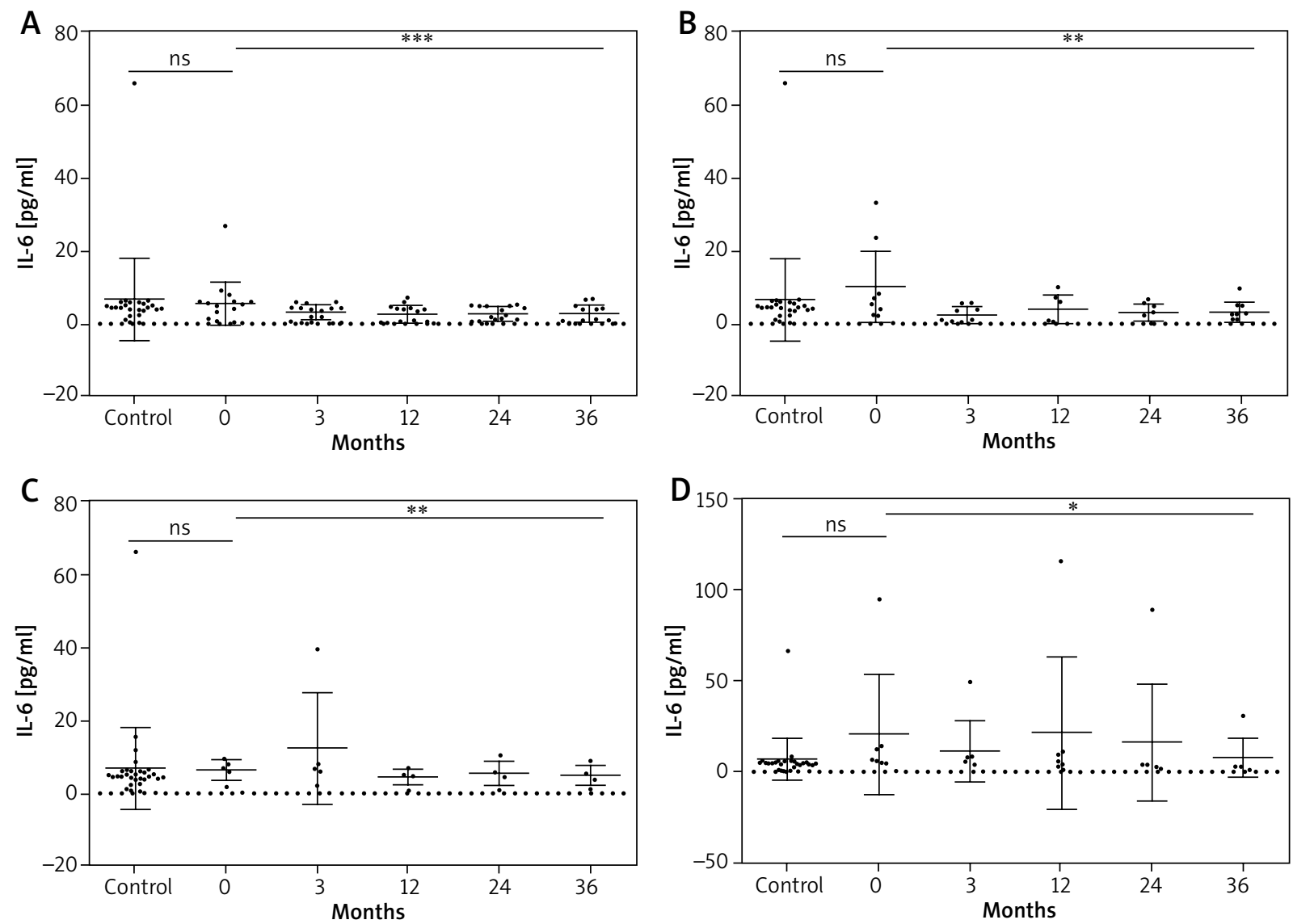

Figure 2. Changes in the IL-6 serum level during biological treatment (A - adalimumab, B - etanercept, $\mathbf{C}-$ ustekinumab, D - infliximab). Data shown as means \pm SEM, ${ }^{*} p<0.05,{ }^{\star *} p<0.01,{ }^{\star \star *} p<0.001$

healthy volunteers. After a 16-week adalimumab therapy, the IL-22 mRNA expression in lesional skin decreased significantly. Moreover, IL-22 mRNA gene expression correlated with $B S A(B S A R=0.63$ at week 0 ) but not with PASI (PASI $R=0.28$ at week 0 ).

IL-6 is one of the most important proinflammatory cytokines produced by monocytes, fibroblasts, endothelial cells, adipocytes and normal human keratinocytes under the influence of IL-17F [24-26]. It inhibits the proliferation of regulatory $T$ lymphocytes, and activates Th17 cells, thus maintaining inflammation. IL-6 stimulates the inflow of T lymphocytes to the epidermis, moreover, it participates in the process of growth and differentiation of keratinocytes [27].

Numerous scientific studies have proven elevated levels of IL- 6 in the skin and sera of patients with psoriasis $[10,11]$. It is a marker of disease activity and its concentration is proportional to the severity of skin changes [23]. Literature data also suggest that it may be a good indicator of response to treatment, reflecting the efficacy of psoriasis therapy $[10,11,23]$. In addition, the increased propensity to the Koebner symptom has been shown to be associated with elevated IL-6, mast cells and IL-6 receptor (IL-6R) in the skin of the patients [28].
Table 5. Results of post-hoc (Tukey or Dunn's) test for each study group: IL-6 and IL-22. Only statistically significant results presented

\begin{tabular}{lll}
\hline Study group & \multicolumn{1}{c}{$\begin{array}{c}\text { Multiple } \\
\text { comparisons }\end{array}$} & P-value \\
\hline IL-6 [pg/ml]: & \multicolumn{1}{c}{0 vs. 12} & 0.0006 \\
\hline Adalimumab & 0 vs. 24 & 0.0208 \\
\cline { 2 - 3 } & 0 vs. 36 & 0.0018 \\
\hline Etanercept & 0 vs. 3 & 0.0046 \\
\hline Infliximab & 0 vs. 36 & 0.0132 \\
\hline Ustekinumab & 3 vs. 12 & 0.0137 \\
\hline IL-22 [pg/ml]: & & \\
\hline Adalimumab & 0 vs. 12 & 0.0247 \\
\cline { 2 - 3 } & 0 vs. 24 & 0.0004 \\
\cline { 2 - 3 } & 0 vs. 36 & 0.0040 \\
\hline Infliximab & 0 vs. 36 & 0.0235 \\
\hline
\end{tabular}

It has been described that effective systemic treatment (methotrexate or UVB phototherapy) results in a decrease in serum IL-6 $[29,30]$. In our study group 
Table 6. Results of multivariate regression between PASI, IL-6 and IL-22 serum concentration

\begin{tabular}{lcccccc}
\hline Study group & Statistics & Baseline & $\mathbf{3}^{\text {rd }}$ month & $\mathbf{1 2}^{\text {th }}$ month & $\mathbf{2 4}^{\text {th }}$ month & $\mathbf{3 6}^{\text {th }}$ month \\
\hline Adalimumab & $R$ & 0.2003 & 0.5500 & 0.2670 & 0.2116 & 0.2779 \\
\cline { 2 - 7 } & $P$-value & 0.7207 & 0.0560 & 0.5535 & 0.6932 & 0.5256 \\
\hline \multirow{2}{*}{ Etanercept } & $R$ & 0.5374 & 0.4345 & 0.6862 & 0.3090 & 0.6022 \\
\cline { 2 - 7 } & $P$-value & 0.2559 & 0.4331 & 0.0784 & 0.6694 & 0.1650 \\
\hline Ustekinumab & $R$ & 0.4788 & 0.4351 & 0.9335 & 0.5851 & 0.3988 \\
\hline Infliximab & $P$-value & 0.7707 & 0.8107 & 0.1287 & 0.6577 & 0.8410 \\
\cline { 2 - 7 } & $R$ & 0.2004 & 0.6353 & 0.9568 & 0.2406 & 0.2629 \\
\hline$P$-value & 0.9213 & 0.3556 & 0.0071 & 0.8875 & 0.8665 \\
\hline
\end{tabular}

$P$-value of 0.05 or less was considered as statistically significant, $R$-correlation coefficient.

mean IL-6 serum concentrations did not differ significantly at baseline from these observed in controls. However under the influence of biologic therapy, a significant decrease in its mean serum level was observed in all analysed groups (treated with adalimumab, etanercept, infliximab and ustekinumab) $(p<0.05)$.

\section{Conclusions}

According to obtained results, the IL-6 and IL-22 serum concentration may be an accurate marker of response to antipsoriatic therapy, even though not strictly correlated with PASI index. Biologic therapy in psoriasis allows for long-term clinical improvement expressed through not only the remission of skin lesions, but also through lowering serum concentrations of pro-inflammatory interleukins. Further investigations on a larger group of patients is needed.

\section{Acknowledgments}

The study was funded by grant UMO-2013/11/B/ NZ5/00037 and Medical University of Lodz, project no. 503/5-064-01/503-01 and 503/1-152-01/503-11-002.

\section{Conflict of interest}

The authors declare no conflict of interest.

\section{References}

1. Parisi R, Symmons DP, Griffiths CE, et al. Identification and Management of Psoriasis and Associated ComorbidiTy (IMPACT) project team. Global epidemiology of psoriasis: a systematic review of incidence and prevalence. J Invest Dermatol 2013; 133: 377-85.

2. Schlaak JF, Buslau M, Jochum W, et al. T cells involved in psoriasis vulgaris belong to the Th1 subset. J Invest Dermatol 1994; 102: 145-9.
3. Lew W, Bowcock AM, Krueger JG. Psoriasis vulgaris: cutaneous lymphoid tissue supports T-cell activation and "type 1" inflammatory gene expression. Trends Immunol 2004; 25 : 295-305.

4. Martin DA, Towne JE, Kricorian G, et al. The emerging role of IL-17 in the pathogenesis of psoriasis: preclinical and clinical findings. J Invest Dermatol 2013; 133: 17-26.

5. Chiricozzi A, Guttman-Yassky E, Suárez-Farińas M, et al. Integrative responses to IL-17 and TNF in human keratinocytes account for key inflammatory pathogenic circuits in psoriasis. J Invest Dermatol 2011; 131: 677-87.

6. Brito-Luna M, Villanueva-Quintero DG, Sandoval-Talamantes AK, et al. Correlation of IL-12, IL-22, and IL-23 in patients with psoriasis and metabolic syndrome. Preliminary report. Cytokine 2016; 85: 130-6.

7. Luan L, Ding Y, Han S, et al. An increased proportion of circulating Th22 and Tc22 cells in psoriasis. Cell Immunol 2014; 290: 196-200.

8. Caproni M, Antiga E, Melani L, et al. Serum levels of IL-17 and IL-22 are reduced by etanercept, but not by acitretin, in patients with psoriasis: a randomized-controlled trial. J Clin Immunol 2009; 29: 210-4.

9. Cordiali-Fei P, Bianchi L, Bonifati C, et al. Immunologic biomarkers for clinical and therapeutic management of psoriasis. Mediators Inflamm 2014; 2014: 236060.

10. Arican O, Aral M, Sasmaz S, et al. Serum levels of TNF-alpha, IFN-gamma, IL-6, IL-8, IL-12, IL-17 and IL-18 in patients with active psoriasis and correlation with disease severity. Mediators Inflamm 2005; 5: 273-9.

11. Neuner P, Urbanski A, Trautinger F, et al. Increased IL-6 production by monocytes and keratinocytes in patients with psoriasis. J Invest Dermatol 1991; 97: 27-33.

12. Chiricozzi A, Romanelli P, Volpe E, et al. Scanning the Immunopathogenesis of Psoriasis. Int J Mol Sci 2018; 19: 179.

13. Gottlieb SL, Gilleaudeau P, Johnson R, et al. Response of psoriasis to a lymphocyte-selective toxin (DAB389IL-2) suggests a primary immune, but not keratinocyte, pathogenic basis. Nat Med 1995; 1: 442-7.

14. Abrams JR, Lebwohl MG, Guzzo CA, et al. CTLA4lg-mediated blockade of T-cell costimulation in patients with psoriasis vulgaris. J Clin Investig 1999; 103: 1243-52.

15. Kim J, Krueger JG. The immunopathogenesis of psoriasis. Dermatol Clin 2015; 33: 13-23. 
16. Lowes MA, Suarez-Farinas M, Krueger JG. Immunology of psoriasis. Annu Rev Immunol 2014; 32: 227-55.

17. Mashiko S, Bouguermouh S, Rubio M, et al. Human mast cells are major IL-22 producers in patients with psoriasis and atopic dermatitis. J Allergy Clin Immunol 2015; 136: 351-9.

18. Zheng Y, Danilenko DM, Valdez P, et al. Interleukin-22, a T(H)17 cytokine, mediates IL-23-induced dermal inflammation and acanthosis. Nature 2007; 445: 648-51.

19. Wilson NJ, Boniface K, Chan JR, et al. Development, cytokine profile and function of human interleukin 17- producing helper T cells. Nature Immunol 2007; 8: 950-7.

20. Sugiyama H, Gyulai R, Toichi E, et al. Dysfunctional blood and target tissue $C D 4+C D 25$ high regulatory T cells in psoriasis: mechanism underlying unrestrained pathogenic effector T cell proliferation. J Immunol 2005; 174: 164-73.

21. Res PCM, Piskin G, de Boer OJ, et al. Overrepresentation of IL-17A and IL-22 producing CD8 T cells in lesional skin suggests their involvement in the pathogenesis of psoriasis. PLoS One 2010; 5: e14108.

22. Bai F, Zheng W, Dong Y, et al. Serum levels of adipokines and cytokines in psoriasis patients: a systematic review and meta-analysis. Oncotarget 2018; 9: 1266-78.

23. Balato A, Schiattarella M, Di Caprio R, et al. Effects of adalimumab therapy in adult subjects with moderate-to-severe psoriasis on Th17 pathway. J Eur Acad Dermatol Venereol 2014; 28: 1016-24

24. Gerdes S, Osadtschy S, Rostami-Yazdi M, et al. Leptin, adiponectin, visfatin and retinol-binding protein-4 - mediators of comorbidities in patients with psoriasis? Exp Dermatol 2012; 21: 43-7.

25. Kershaw EE, Flier JS. Adipose tissue as an endocrine organ. J Clin Endocrinol Metab 2004; 89: 2548-56.

26. Fujishima S, Watanabe H, Kawaguchi M, et al. Involvement of IL-17F via the induction of IL-6 in psoriasis. Arch Dermatol Res 2010; 302: 499-505.

27. Pietrzak AT, Zalewska A, Chodorowska G, et al. Cytokines and anticytokines in psoriasis. Clin Chim Acta 2008; 394: 7-21.

28. Suttle MM, Nilsson G, Snellman E, et al. Experimentally induced psoriatic lesion associates with interleukin (IL)- 6 in mast cells and appearance of dermal cells expressing IL-33 and IL-6 receptor. Clin Exp Immunol 2012; 169: 311-9.

29. Elango T, Dayalan H, Subramanian S, et al. Serum interleukin-6 levels in response to methotrexate treatment in psoriatic patients. Clin Chim Acta 2012; 413: 1652-6.

30. Lo YH, Torii K, Saito C, et al. Serum IL-22 correlates with psoriatic severity and serum IL6 correlates with susceptibility to phototherapy. J Dermatol Sci 2010; 58: 225-7. 